\title{
Neuroprotective Effect of Sacha Inchi Oil (Plukenetia volubilis L.) in an Experimental Model of Epilepsy
}

\author{
Oscar Herrera-Calderon ${ }^{1, *}$, Ricardo Ángel Yuli-Posadas ${ }^{2}$, Johnny Aldo Tinco-Jayo ${ }^{3}$, Edwin Enciso-Roca ${ }^{3}$, César \\ Franco-Quino ${ }^{4}$, Victor Chumpitaz-Cerrate ${ }^{5}$, Linder Figueroa-Salvador ${ }^{6}$
}

\section{Oscar Herrera-Calderon ${ }^{1, *}$, Ricardo Ángel Yuli-Posadas², Johnny Aldo Tinco-Jayo ${ }^{3}$, Edwin Enciso-Roca ${ }^{3}$, César Franco- Quino ${ }^{4}$, Victor Chumpitaz- Cerrate $^{5}$, Linder Figueroa- Salvador ${ }^{6}$}

${ }^{1}$ Faculty of Pharmacy and Biochemistry, Universidad Nacional Mayor de San Marcos, Lima, PERU.

${ }^{2}$ Universidad Continental, Huancayo, PERU. ${ }^{3}$ Faculty of Health Sciences, Universidad Nacional de San Cristóbal de Huamanga, Ayacucho, PERU.

${ }^{4}$ School of Public Health and Administration, Universidad Peruana Cayetano Heredia, Lima, PERU.

${ }^{5}$ Laboratory of Pharmacology, Universidad Científica Del Sur, Lima, PERU.

${ }^{6}$ School of Medicine, Universidad Peruana de Ciencias Aplicadas, Lima PERU.

\section{Correspondence}

\section{Dr. Oscar Herrera Calderon}

Jr Puno 1002, Cercado de Lima, Faculty of Pharmacy and Biochemistry, Universidad Nacional Mayor de San Marcos, Lima, PERU

Phone no: +51956550510

E-mail: oherreraca@unmsm.edu.pe History

- Submission Date: 02-09-2019;

- Review completed: 11-10-2019;

- Accepted Date: 11-11-2019.

DOI : 10.5530/pj.2019.11.243

Article Available online

http://www.phcogj.com/v11/i6s

\section{Copyright}

(c) 2019 Phcogj.Com. This is an open access article distributed under the terms of the Creative Commons Attribution 4.0 International license.

\section{ABSTRACT}

Background: Experimental studies have demonstrated that fatty acids such as omega 3 and 6 have anti-inflammatory, anticonvulsant, cardio protective and anti-tumor effects. Objective:The main objective was to determine the protective effect of sacha inchi oil on pentylenetetrazoleinduced seizures in albino mice. Material and Methods: Thirty male Balb/C albino mice of 8 weeks of age were purchased from the National Institute of Health (Lima-Peru). The animals were divided into 5 groups of 6 animals each one. Group I: Control; PTZ (pentylenetetrazole $80 \mathrm{mg} / \mathrm{kg}$, s.c.). II: PTZ + Diazepam (1 mg / kg; s.c.). Group III, IV, V: PTZ + sacha inchi oil at single doses of $250,500,1000 \mathrm{mg} / \mathrm{kg}$ respectively orally. Sacha inchi oil was administered 30 minutes before induction of seizures by PTZ. Next, various parameters such as latency, seizure frequency, duration and score were scored according to Racine scale. The program Graph Pad Prism v.4 was used for statistical analysis. Results: As result, the experimental group treated with sacha inchi oil at maximum dose of $1000 \mathrm{mg} / \mathrm{kg}$ showed better results in response to PTZ induced seizure; low levels of seizures, frequency and duration $(P<0.001$; ANOVA, $P<0.001$ Post-hoc Dunnett test). Conclusion: It is concluded that Sacha inchi oil presented anticonvulsant effect at the highest doses tested being very similar to Diazepam. The main mechanism could be by reducing free radical and improving GABA levels in the brain Key words: Sacha inchi, Plukenetia volubilis, Convulsion, Epilepsy, Pentylenetetrazole, Omega.

\section{INTRODUCTION}

The modern concept of epilepsy proposed by the International League Against Epilepsy involves a chronic disorder of the brain characterized by an enduring disposition towards recurrent unprovoked seizures. The diagnosis requires at least 2 seizures occurring greater than 24 hours apart or one seizure with a relevant abnormal electroencephalographic pattern or brain scan suggesting a high probability of a second seizure. ${ }^{1}$ Approximately, more than 50 million worldwide have been diagnosed with epilepsy, representing a serious problem of public health for all ages, genders and social groups. Medical reports have shown an incidence rate of epilepsy of 50 per 100 000 habitants in developed countries and 100 per 100000 in developing countries. ${ }^{2}$

Some classic anticonvulsant drugs have shown their efficacy in the prophylaxis of convulsions (symptomatic acute), but not of unprovoked seizures (epileptic). Pathophysiology of epilepsy is known for disorders of neural depolarization membrane, neural morphology and ionic environment. These alterations cause an imbalance of excitatory neurotransmitters (glutamate and aspartate) and inhibitory (gamma amino butyric acid known as GABA). ${ }^{3}$

One of the experimental models to induce seizures is pentylenetetrazole (PTZ), this is a chemical reagent which produces generalized discharges and acts as a noncompetitive antagonist of GABA receptors, also induces oxidative stress in the brain altering the normal metabolism phospholipids and proteins, oxidative stress is directly associated as one of the factors that causes epilepsy. ${ }^{4}$

Otherwise, evidences about possible anticonvulsant properties for n-3 PUFA, including a-linolenic, eicosapentaenoic, and docosahexaenoic acids, has been involving to cell cultures and ex vivo preparations. The main explanation is due to $n-3$ PUFA confer protection against seizures by increasing the threshold for action potentials and by extending the refractory period in neurons. This mechanism appears to result from a partial inhibition of sodium and calcium voltage-gated channels. ${ }^{5}$

Plukenetia volubilis L. (P. volubilis), which belongs to the family Euphorbiaceae has been used historically in the Amazon population as a food source and cosmetics, also is known as Sacha inchi. ${ }^{6}$ Sacha inchi oil derived from the seeds and obtained by cold pressing presents triglycerides, tocopherols and polyphenols mainly ( $\gamma$-tocopherol). It is one of the best sources of omega-3 (45-55\%) and having more unsaturated content fatty acid (35-65\%). ${ }^{7}$

Various studies related to polyunsaturated fatty acids (PUFAs) with neuroprotective effect, ${ }^{8}$ therefore, this research has as main objective: To evaluate the anticonvulsant effect of Sacha inchi oil (Plukenetia volubilis L.) on PTZ-induced seizures in albino mice.

Cite this article: Herrera-Calderon O, Yuli-Posadas RA, Tinco-Jayo JA, Enciso-Roca E, FrancoQuino C, Chumpitaz-Cerrate V, et al. Neuroprotective Effect of Sacha Inchi Oil (Plukenetia volubilis L.) in an Experimental Model of Epilepsy. Pharmacog J. 2019;11(6)Suppl:1591-6. 


\section{MATERIALS AND METHODS}

\section{Animals}

A total of thirty male albinos Balb / C mice (20-30 g), were purchased from the National Institute of Health (Lima-Peru). Mice were placed in a Plexiglas's cage with access to food pellets and water ad libitum, housed in an animal room with controlled temperature $\left(22-24{ }^{\circ} \mathrm{C}\right)$ and 12/12 h light / dark. All mice were divided into five groups of six animals each one, acclimated to the laboratory 15 days prior to the experiments. The experimental protocol was carried out in accordance with the guidelines established by the European Union Animal Care (CCE Council 86/609).

\section{Collection of plant material}

Sacha inchi seeds were collected from Pucallpa, Ucayali, Peru in June 2018. Next, $3 \mathrm{Kg}$ of sample was stored in kraft paper being transported to the laboratory. Botanical identification of plant material was classified and voucher specimen (13-2014-USM-MHN) was deposited at the National Herbarium of the Universidad Nacional Mayor de San Marcos, Lima, Peru.

\section{Oil preparation and physicochemical analysis}

The extraction is performed by cold pressing method. The obtained oil was stored at room temperature in sealed in amber bottle, physicochemical tests were performed according to AOAC. ${ }^{8}$ Analysis by gas chromatography with flame ionization detector (GC-FID) was used in order to determine the content of polyunsaturated fatty acids presents in sacha inchi oil (Figure 1). ${ }^{9}$

\section{Drugs and chemicals}

Pentylenetetrazole (PTZ), 1,1-diphenyl-2-picrylhydrazyl (DPPH), Trolox, (Sigma-Aldrich, St. Louis, MO, USA) and diazepam (Medifarma Pharmaceuticals Co.). All other chemicals used were of analytical grade.

\section{DPPH antioxidant activity}

The antioxidant activity of Sacha inchi oil and the positive control (Trolox) was estimated based on the Brand-Williams method et al. ${ }^{10}$ Aliquots $(100 \mathrm{uL})$ at various concentrations of oil and Trolox were mixed with $900 \mathrm{uL}$ of DPPH solution diluted with dichloromethane. The solution was stirred and stored at room temperature for 30 minutes in the dark. The absorbance of the reaction solution was measured by spectrophotometric method at $517 \mathrm{~nm}$. The percent antioxidant activity was calculated according to the equation: \% Antioxidant activity $=$ [(ABS control - ABS sample) / ABS control $] \times 100$.

Where: ABS control: control absorbance; ABS sample: sample absorbance

\section{Anticonvulsant effect}

Mice were randomly divided into five groups $(n=6)$ and were treated according to the experimental protocol: Group I: Control; PTZ (pentylenetetrazole $80 \mathrm{mg} / \mathrm{kg}$, s.c.). II: PTZ + Diazepam (1 mg / kg; s.c.). Group III, IV, V: PTZ + sacha inchi oil at single doses of 250, 500, $1000 \mathrm{mg} / \mathrm{kg}$ respectively orally. Treatments were administered 30 minutes before administration of PTZ (80 mg / kg, ip). Diazepam (1 $\mathrm{mg} / \mathrm{kg}$, ip) was administered 15 minutes, respectively, before injection of PTZ. Animals were placed in a Plexiglas's cage $(20 \times 20 \times 20 \mathrm{~cm})$ and observed for 30 minutes to determine the onset latency of seizures, frequency of seizures, mortality and duration of a seizure. Animals that survived after that period of time were considered protected. In addition, each attack was classified according to Racine scale modified as follows: 1-mouth and facial movements; 2-head nodding; 3-legs movement; 4-lift; 5-stretch and fall. ${ }^{11,12}$

\section{Biochemical parameters}

Two biochemical parameters were determined by spectrophotometry in order to determine the effect of sacha inchi oil on GABA neurotransmitter and MDA as antioxidant marker in vivo.

\section{GABA estimate by spectrophotometry}

GABA (gamma aminobutyric acid) from different experimental groups was determined and isolated immediately for transferring to a homogenization tube containing $5.0 \mathrm{~mL}$ of $0.01 \mathrm{M}$ hydrochloric acid. The brain homogenate was transferred to a bottle containing $8.0 \mathrm{ml}$ of alcohol all frozen and held for $1 \mathrm{~h}$ at $0^{\circ} \mathrm{C}$. The contents were centrifuged for $10 \mathrm{~min}$ at $5000 \mathrm{~g}$, the supernatant was collected in petridish. The precipitate was washed with $5 \mathrm{~mL}$ of $70 \%$ alcohol for three times and the washings were combined with the supernatant. Then the samples were evaporated to dryness at $70^{\circ} \mathrm{C}$ in a water bath. Dried samples were added $1 \mathrm{~mL}$ of water and $2 \mathrm{~mL}$ of chloroform and centrifuged at $2000 \mathrm{~g}$. the upper phase containing GABA $(2.0 \mathrm{~mL})$ was separated and $10 \mathrm{~mL}$ of this was applied as spots on Whatman $\left(\mathrm{N}^{\circ} 41\right)$. The mobile phase consisted of n-butanol $(50 \mathrm{~mL})$ acetic acid $(12 \mathrm{~mL})$ and water $(60 \mathrm{~mL})$.

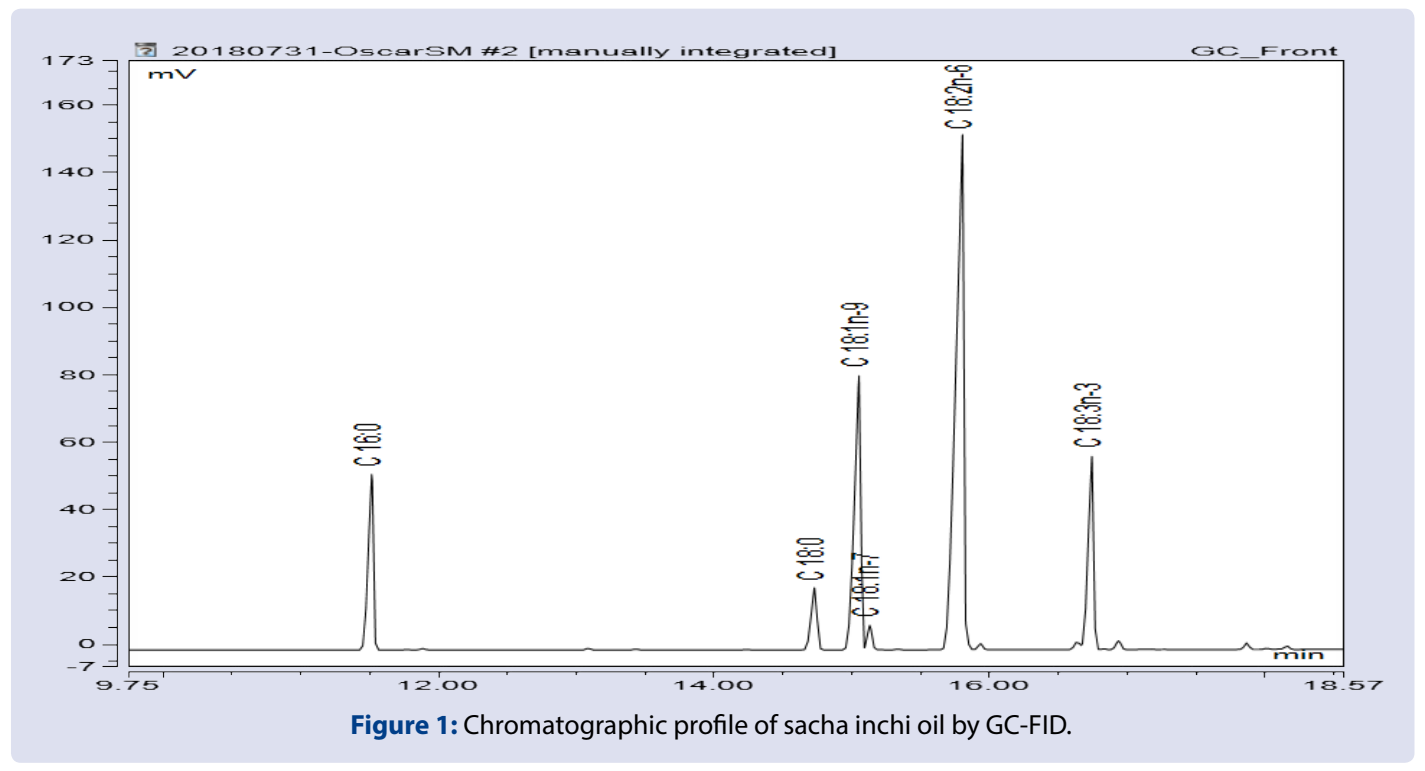


The paper chromatogram was developed with an ascending technique. The paper was dried in hot air and then spread with a solution of ninhydrin $0.5 \%$ in $96 \%$ ethanol. The paper was dried for 1 hour at $90^{\circ}$ C. The blue color spot developed paper was sheeted and heated with 2 $\mathrm{mL}$ of ninhydrin solution in water bath for 5 minutes. water $(5.0 \mathrm{~mL})$ was added to the solution and maintained for $1 \mathrm{~h}$. The supernatant $(2.0 \mathrm{~mL})$ was decanted and the absorbance was measured at $570 \mathrm{~nm}$ by spectrophotometry. GABA standard was used to extrapolate the absorbances of the samples. ${ }^{13}$

\section{Estimation of lipid peroxidation}

Lipid peroxidation was detected by measuring malondialdehyde (MDA) determined by the method of Buege and Aust. ${ }^{14}$

\section{Statistical evaluation}

Statistical analyzes were performed using Graph pad prism v4. The parameters measured are expressed as mean \pm standard error of the mean, percentage of antioxidant activity. Linear regression was used to obtain $\mathrm{IC}_{50}$. The anticonvulsant effect was analyzed using one-way ANOVA followed by Dunnett's test. The results were presented as mean \pm SD $(\mathrm{n}=6)$. Values with $P<0.05$ were considered statistically significant.

\section{RESULTS}

\section{Chemical characteristics of Sacha inchi oil}

The chemical characteristics of sacha inchi oil are described in Table 1 such as values of refractive index, density, free fatty acids, iodine index, saponification value, peroxide value and conjugated dienes of crude oil.

In the analysis by gas chromatography for the presence of palmitic acid it was determined: (C16: 0) $10.67 \pm 0.06 \%$, stearic acid (C18: 0):4.36 \pm 0.01\%, Oleic acid (C18: 1): $21.10 \pm 0.02 \%$, Linoleic acid (C18: 2):50.36 $\pm 0.01 \%$, a-linolenic acid (C18: 3): $12.20 \pm 0.02 \%$, Vaccenic acid (C18: 7): $1.31 \pm 0.004 \%$.

\section{DPPH radical scavenging}

The antioxidant activity on DPPH free radical four different concentrations $(100.0 ; 500.0 ; 1000.0$ and $2000.0 \mu \mathrm{g} / \mathrm{mL}$ ) with their respective percentages were determined and placed in Table 2. The 50\% inhibitory concentration $\left(\mathrm{IC}_{50}\right)$ was $1350.50 \pm 0.56 \mu \mathrm{g} / \mathrm{mL}$. Moreover, the extract inhibited the radical DPPH in a dose dependent. The extract reduced the DPPH to $75.50 \%$ for $2000 \mu \mathrm{g} / \mathrm{mL}$.

\section{Anticonvulsant effect}

In the anticonvulsant effect, these parameters showed a significant decrease, as the onset of seizures, seizure duration, scoring and seizure frequency $(P<0.01)$ similar to diazepam group (Figure 2$)$. Treatment with Sacha inchi oil (500 and $1000 \mathrm{mg} / \mathrm{kg}$, po) and diazepam (1 mg / kg, ip) showed significant protection against PTZ seizures (Table 3) induced.

\section{DISCUSSION}

The scientific literature has shown several components from $P$. volubilis seeds. especially high content of fatty acids such as $\alpha$-linolenic acid $(\alpha-\operatorname{Ln})(\omega 3,12.8-16.0 \mathrm{~g} / 100 \mathrm{~g}$ seed $)$, followed by linoleic fatty acid $(\mathrm{L})(\omega 6,12.4-14.1 \mathrm{~g} / 100 \mathrm{~g}$ seed $)$. The $\omega 6 / \omega 3$ ratio within the range of $0.83-1.09 .{ }^{15}$ The $\gamma$ and $\delta$ tocopherols were the most important tocopherols, while the most representative phytosterols have been the $\beta$-sitosterol and stigmasterol. Furthermore, Sacha inchi oil contains unsaturated fatty acids such as linolenic acid (omega 3) (C18: 3), linoleic acid (omega 6) (C18:2) and oleic acid (omega 9) (C18: 1). Also, it has been reported palmitic acid (C16: 0)

\section{Table 1: Chemical characteristics of sacha inchi oil.}

\begin{tabular}{|c|c|}
\hline Physicochemical characteristics & Sacha Inchi* \\
\hline Refractive index & $1.478 \pm 0.00$ \\
\hline Density at $25^{\circ} \mathrm{C}$ & $0.920 \pm 0.02$ \\
\hline $\begin{array}{c}\text { Free fatty acids } \\
(\% \text { Oleic acid })\end{array}$ & $0.200 \pm 0.02$ \\
\hline $\begin{array}{l}\text { Iodine index } \\
\text { ( } g \text { of } \mathrm{I} / 100 \mathrm{~g} \text { ) }\end{array}$ & $93.80 \pm 0.40$ \\
\hline $\begin{array}{c}\text { Peroxide values } \\
\mathrm{mEqO}_{2} / \mathrm{Kg}\end{array}$ & $0.890 \pm 0.05$ \\
\hline $\begin{array}{l}\text { Saponification index } \\
(\mathrm{mg} / \mathrm{KOH} / \mathrm{g})\end{array}$ & $185.50 \pm 0.20$ \\
\hline
\end{tabular}

${ }^{\star}$ Average of three repetitions \pm standard deviation.

Table 2: Antioxidant activity of Sacha inchi oil against DPPH radical.

\begin{tabular}{ccc}
\hline $\begin{array}{c}\text { Concentration } \\
\mu \mathrm{g} / \mathrm{mL}\end{array}$ & \multicolumn{2}{c}{$\%$ Antioxidant Activity } \\
\cline { 2 - 3 } 2000.0 & $75.50 \pm 2.1$ & Trolox \\
1000.0 & $43.25 \pm 1.0$ & $97.30 \pm 1.0$ \\
500.0 & $19.75 \pm 1.1$ & $95.20 \pm 2.0$ \\
100.0 & $9.80 \pm 0.6$ & $96.61 \pm 1.0$ \\
\hline
\end{tabular}

*Average of three repetitions \pm standard deviation.

Table 3: Protection of sacha inchi oil on PTZ-induced seizures.

\begin{tabular}{cccccc}
\hline \multirow{2}{*}{ Indicator } & \multicolumn{5}{c}{$\mathrm{n}=6$} \\
\cline { 2 - 6 } & $\mathrm{PTZ}$ & $\mathrm{DZP}$ & 250 & 500 & 1000 \\
\hline Alive & $0 / 6$ & $6 / 6$ & $3 / 6$ & $5 / 6$ & $6 / 6$ \\
$\begin{array}{c}\text { Protection } \\
(\%)\end{array}$ & 0 & 100 & 50 & 83 & 100 \\
\hline
\end{tabular}

DZP: Diazepam; PTZ: pentylenetetrazole.

and stearic acid (C:18) by gas chromatography and these findings are within the range established and reported by Maurer et al. ${ }^{16}$

In regard to oxidative stress, increased formation of free radicals, particularly reactive oxygen species (ROS) produces a high intracellular concentration of $\mathrm{Ca}^{2+}$, which is involved in mechanisms of neuronal necrosis or apoptosis system. ${ }^{17}$ The relationship between free radicals and seizures might have a multiple mechanism, for example, free radicals may induce seizures by direct inactivation of glutamine synthase, establishing abnormal release of excitatory neurotransmitters such as glutamic acid. Also, the onset of convulsions induced by oxygen in animals correlate with decreased levels of GABA in the cerebral cortex due to inhibition of glutamate decarboxylase by oxygen free radicals. ${ }^{18-20}$

The antioxidant activity demonstrated in this study on DPPH radical, and MDA in vivo may be related to the anticonvulsant effect. ${ }^{19}$ Seghatoleslam et al. studied the administration of ascorbic acid and flavonoids of $N$. sativa in animal studies demonstrating the reduction of neuronal damage triggered by free radicals, which are particularly high in the processes of inflammation and neurodegenerative disorders. Also animals pretreated with ascorbic acid, before induction of seizures by pilocarpine have shown a significant reduction of $60 \%$ in the frequency of brain damage hippocampal, the latency to the first seizures, suppression behavioral convulsive episodes, followed by decreased lipid peroxidation (MDA and nitric oxide (NO).21,22

It is known that omega-3 fatty acids can improve GABAergic transmission in animals with epilepsy by stimulating the formation of new hippocampal interneurons or by altering the expression of calcium-binding proteins. ${ }^{23}$ On the other hand, polyunsaturated fatty acids, including n-3 (omega-3) fatty acids such as eicopentanoic acid (EPA), docosahexaenoic acid (DHA) and n-6 fatty acid (omega-6) as dihomo-c-linolenic acid and arachidonic acid are present in high levels 


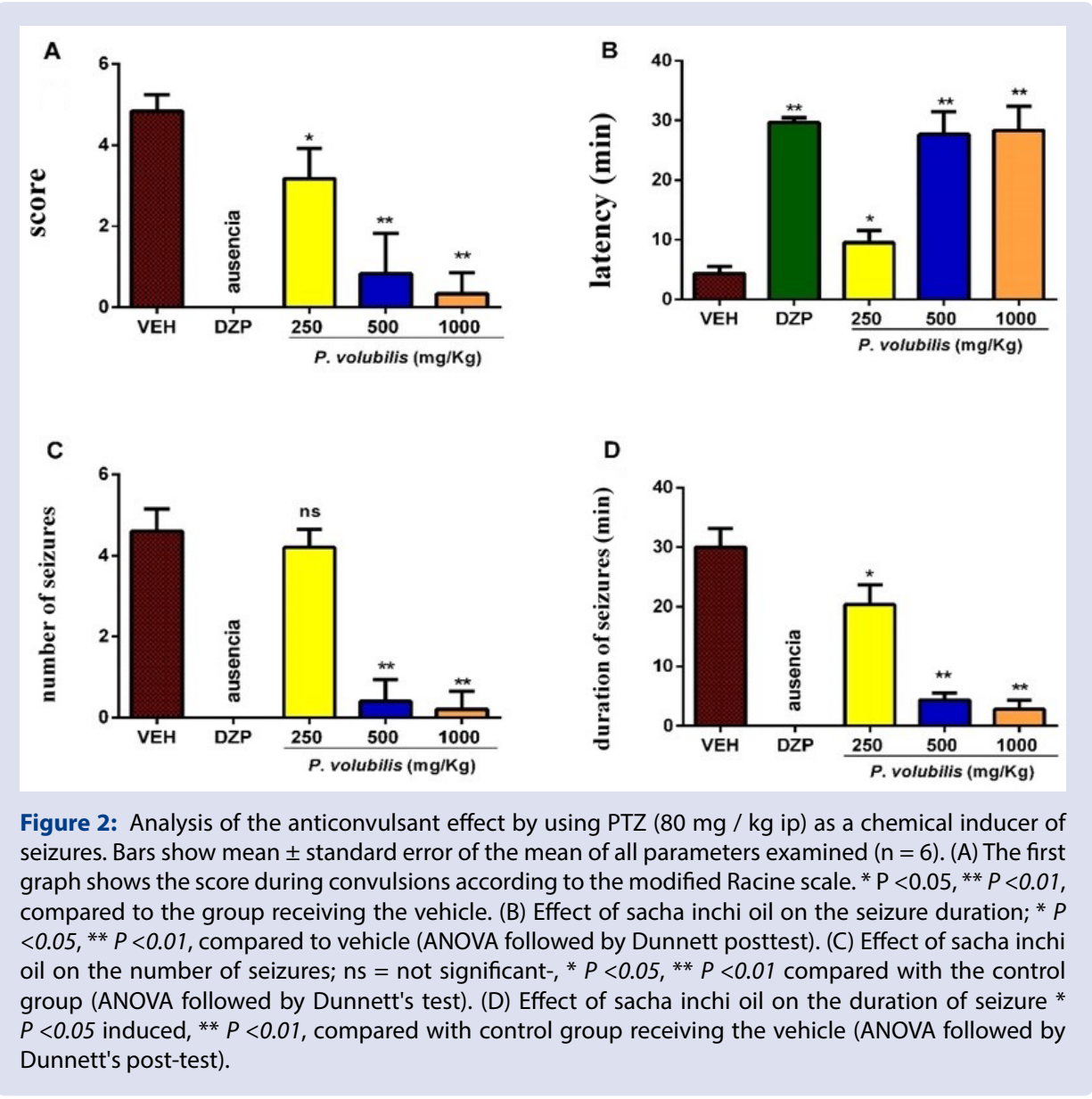

Table 4: Estimate of GABA and MDA in mouse brain.

\begin{tabular}{cccccc}
\hline \multirow{2}{*}{ Indicator } & \multicolumn{5}{c}{$\mathrm{n}=6$} \\
\cline { 2 - 5 } & $\mathrm{PTZ}$ & $\mathrm{DZP}$ & 250 & 500 & 1000 \\
\hline $\begin{array}{c}\mathrm{GABA}(\mathrm{ng} / \mathrm{g} \text { tissue) } \\
\left(\mathrm{MDA} 10^{-6} \mathrm{~mol} / \mathrm{g}\right. \\
\text { brain tissue) }\end{array}$ & $12 \pm 1.5$ & $87 \pm 1.8^{* *}$ & $35 \pm 2.5^{*}$ & $62 \pm 1.2^{* *}$ & $73 \pm 1.1^{* *}$ \\
\hline
\end{tabular}

MDA: malondialdehyde; DZP: Diazepam; PTZ: pentylenetetrazole; ${ }^{*} P<0.05 ;{ }^{* *} P<0.01$.

in the brain. In humans, the intake of long-chain omega- 3 fatty acids, which are commonly found in fish and food supplements such as fish oil, not only contributes to the development of the central nervous system, but can also reduce the risk of certain nervous system diseases in adults, including epilepsy as reported by Bourre. ${ }^{24}$

Although, there is no well-established importance of polyunsaturated fatty acids in neurodegenerative and neurological diseases, it is necessary carry out further studies in different experimental models to validate the use of Sacha Inchi as co-adjuvant in epileptic diseases.

\section{CONCLUSION}

It is concluded that Sacha inchi oil (P. volubilis L.) showed protective effect on pentylenetetrazole-induced seizures at tested dosages being the most active dose of $1000 \mathrm{mg} / \mathrm{kg}$, and the mechanism would be via the generation of the neurotransmitter GABA and its antioxidant effect.

\section{FUNDING}

$\mathrm{Nil}$

\section{ACKNOWLEDGMENTS}

The authors thank Universidad Nacional Mayor de San Marcos for helping to support this research. Cesar Franco-Quino is a doctoral student studying an Epidemiological Researcher Doctorate at Universidad Peruana Cayetano Heredia under FONDECYT/ CIENCIAACTIVA scholarship EF033-235-2015 and supported by training grant D43 TW007393 awarded by Fogarti International Center of the US National Institutes of Health.

\section{CONFLICTS OF INTEREST}

There are no conflicts of interest.

\section{REFERENCES}

1. Fisher RS: Acevedo C, Arzimanoglou A, Acevedo C, Arzimanoglou A, Bogacz $A$, et al. ILAE official report: a practical clinical definition of epilepsy. Epilepsy. 2014;55:475e482.

2. Xu C, Fan YN, Kan HD, Ren-Jie C, Jiang-Hong L, Ya-Fei L, et al. The novel Relationship Between urban air pollution and epilepsy: a time series study. PLoS One. 2016;11(8):e0161992.

3. Gupta G, K Dua, Kazmi I, Anwar F. Anticonvulsant activity of Morusin isolated from Morus alba: modulation of GABA receptor. Biomed Aging Pathol. $2014 ; 4(1): 29 \mathrm{e} 32$ 
4. Diniz TC, Silva JC, Lima-Saraiva SR, Ribeiro FP, Pacheco AG, de Freitas RM, et al. The role of oxidative stress in flavonoids on epilepsy. Cell Longev Oxid Med. 2015:9.

5. Vreugdenhil M, Bruehl C, Voskuyl RA, Xang JX, Leaf A. Polyunsaturated fatty acids modulate sodium and calcium currents in CA1 neurons. Proc Natl Acad Sci USA. 1996;93:12559-63

6. Gschwind M, Seeck M. Modern management of seizures and epilepsy. Swiss Med Wkly. 2016;146:w14310.

7. Fanali C, Dugo L, Cacciola F, Beccaria M, S Grasso, DASHA M, et al. Chemical characterization of Sacha inchi (Plukenetia volubilis L.) oil. J Agric Food Chem. 2011;59(24):13043-9.

8. Huamán-Saavedra JJ, Silva F, Eltsin B, Pairazamán E, Elizabeth P, CastilloMinaya KY. Effects of intake Plukenetia volubilis Linneo "Sacha inchi" in the lipid profile of young adults. Acta Medica Peruana. 2012;29(3):155-60.

9. Calon F, Cole G. Neuroprotective action of omega-3 polyunsaturated fatty acids against neurodegenerative diseases: evidence from the animal studies. Prostaglandins Leukot Essent Fatty Acids. 2007;77:287-93.

10. Association of Official Analytical Chemists (AOAC). AOAC Official Methods of Analysis. Arlington, VA: AOAC; 2005

11. Fisheries Technology Institute of Peru (ITP), Laboratory of physicochemical analysis. Fatty acid composition by gas chromatography. Lima: ITP; 2003.

12. Brand-WilliamsW, Cuvelier M, Berset $C$. Use of free radical method to Evaluate antioxidant activity. Leb Wiss Technol. 1995;28:25e30.

13. Ingale SP, FP Gandhi. Effect of aqueous extract of Moringa oleifera leaves on pharmacological models of epilepsy and anxiety in mice. Int J Epilepsy. 2016;3:12e19.

14. Racine RJ. Modification of seizure activity by electrical stimulation. II. Motor seizure. Electroencephalogr Neurophysiol Clin. 1972;32:281e294.
15. Tamboli AM, Rub RA, Ghosh P, Bodhankar SL. Antiepileptic activity of lobeline isolated from the leaf of Lobelia nicotianaefolia and Its effect on brain GABA level in mice. Asian Pac J Trop Biomed. 2012:537e542.

16. Buege J, S. Microsomal lipid peroxidation Aust. Methods Enzymol 1978;52:302e310

17. Follegatti-Romero, Piantino CR, R Grimaldi, Cabral FA. Supercritical CO2 extraction of omega-3 rich oil from Sacha inchi (Plukenetia volubilis L.) seeds. J Supercrit Fluids. 2009;49:323-9.

18. Maurer NE, Hatta-Sakoda B, Pascual-Chagman G, Rodriguez-Saone LE. Characterization and authentication of a novel vegetable source of omega-3 fatty acids, Sacha inchi (Plukenetia volubilis L.) oil. Food Chem. 2012;134:117380.

19. Naziroglu M, Akay MB, Celik O, Yildirim MI, Balci E, Yurekli VA. Capparis ovata brain modulates oxidative toxicity and epileptic seizures in rats induced epileptic pentylentetrazol. Neurochem Res. 2013;38(4):780e788.

20. Nozadze M, Mikautadze E, Lepsveridze E, et al. Anticonvulsant activities of Myo-inositol and scyllo-inositol on pentylenetetrazol induced seizures. Seizure. $2011 ; 20: 173 e 176$.

21. Seghatoleslam M, Alipour F, Shafieian R, et al. The effects of Nigella sativa on neural damage after pentylenetetrazole induced seizures in rats. J Tradit Complement Med. 2016;6:262e268.

22. Tomaciello F, Leclercq K, Kaminski RM. Resveratrol protective activity against Lacks acute seizures in mouse models. Neurosci Lett. 2016;632:199e203.

23. DeGiorgio CM, Miller P. n-3 fatty acids (eicosapentanoic and docosahexanoic acids) in epilepsy and for the prevention of sudden unexpected death in epilepsy. Epilepsy Behav. 2008;13:712-3.

24. Bourre JM. Roles of unsaturated fatty acids (especially omega-3 fatty acids) in the brain at various ages and During aging. J Nutr Health Aging. 2004;8:163-74

\section{GRAPHICAL ABSTRACT}

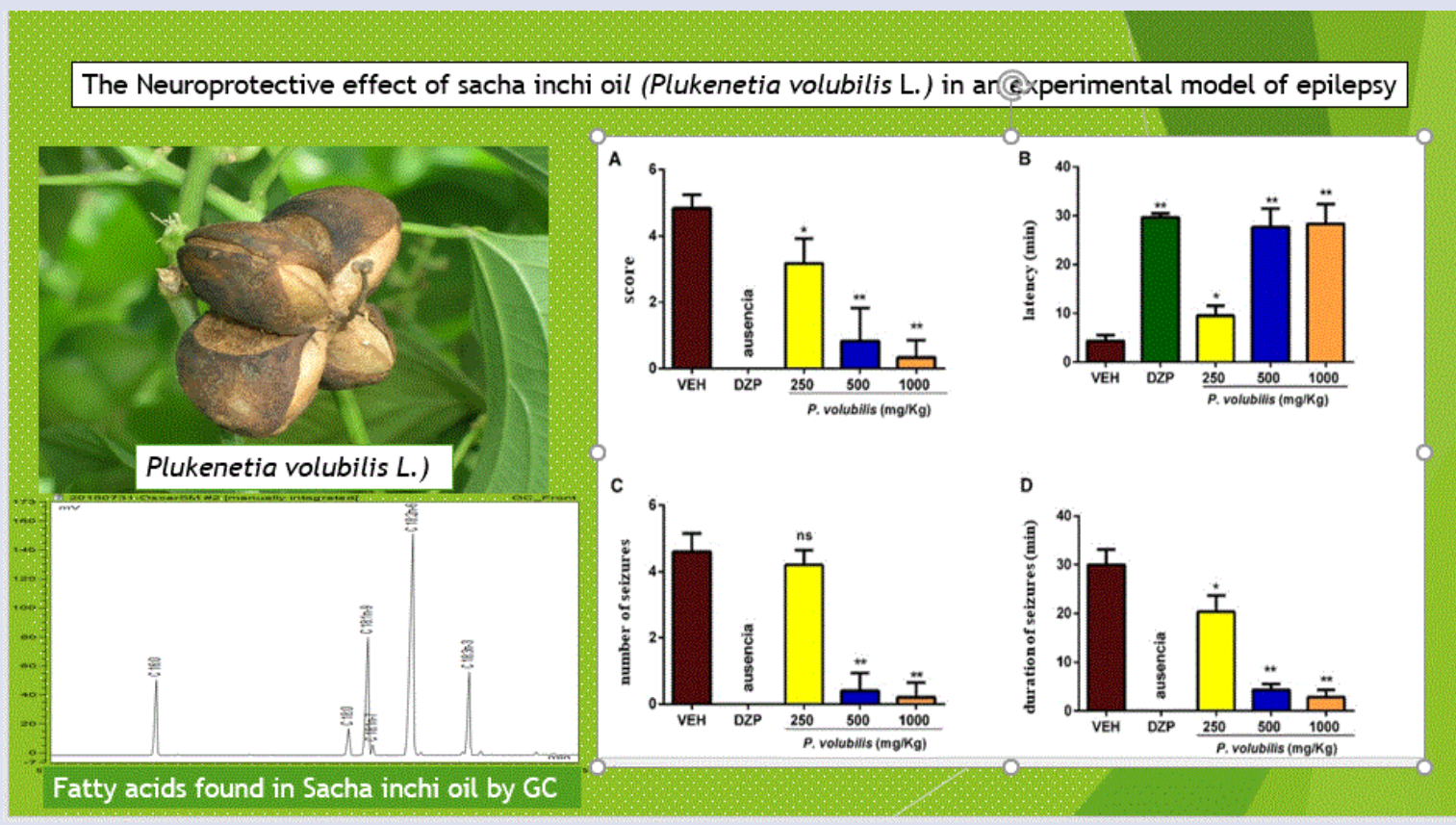

\section{ABOUT AUTHORS}

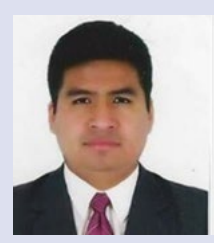

Oscar Herrera-Calderon: His expertise are natural products and the use of animals models to discover new potential drugs against different types of cancer. 


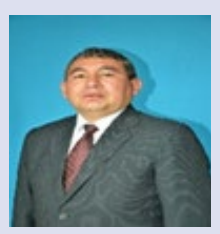

Edwin Enciso-Roca: He works in the Laboratory of toxicology, Faculty of Health Sciences, Universidad Nacional del San Cristóbal de Huamanga.

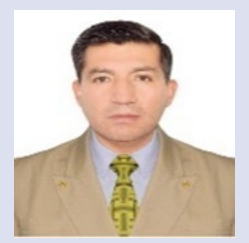

Ricardo Ángel Yuli-Posadas: He works in Universidad Continental, Huancayo, Peru.

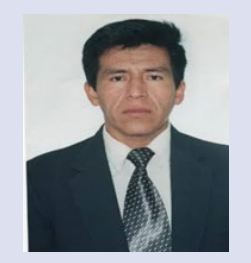

Aldo Tinco-Jayo: He works in the Laboratory of toxicology, Faculty of Health Sciences, Universidad Nacional del San Cristóbal de Huamanga.

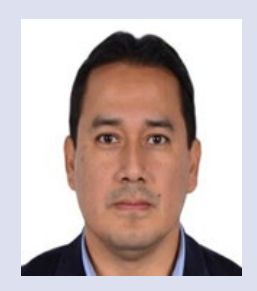

Victor Chumpitaz-Cerrate: Active Member of the International Association for Dental Research (IADR) and the International Association for the Study of Pain (IASP).

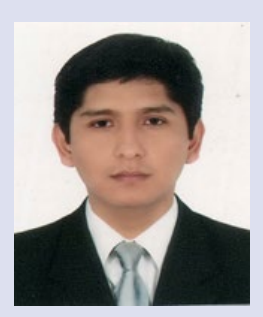

César Franco-Quino: He is studying a doctoral program in the Universidad Peruana Cayetano Heredia, Lima, Peru.

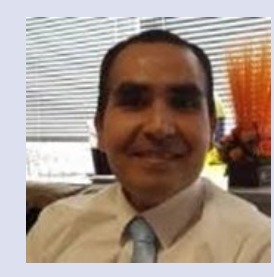

Linder Figueroa-Salvador: He is a professor at the Universidad Peruana de Ciencias Aplicadas (UPC), Lima, Peru.

Cite this article: Herrera-Calderon O, Yuli-Posadas RA, Tinco-Jayo JA, Enciso-Roca E, Franco-Quino C, Chumpitaz-Cerrate V, et al. Neuroprotective Effect of Sacha Inchi Oil (Plukenetia volubilis L.) in an Experimental Model of Epilepsy. Pharmacog J. 2019;11(6) Suppl:1591-6. 